\title{
Human Papillomavirus 16 and 18 Infection in Oral Cancer in Thailand: A Multicenter Study
}

\author{
Nicha Komolmalai ${ }^{1}$, Surawut Pongsiriwet ${ }^{1}$, Nirush Lertprasertsuke ${ }^{2}$, Suree \\ Lekwanavijit ${ }^{2}$, Sompid Kintarak ${ }^{3}$, Ekarat Phattarataratip ${ }^{4}$, Ajiravudh \\ Subarnbhesaj ${ }^{5}$, Kittipong Dhanuthai ${ }^{4}$, Risa Chaisuparat ${ }^{4}$, Anak Iamaroon ${ }^{1 *}$
}

\begin{abstract}
Objectives: To identify the prevalence of high-risk human papillomavirus (HPV) genotypes 16 and 18 among patients with oral squamous cell carcinoma (OSCC) in Thailand and investigate the associations of p16 expression and HPV16/18 with the demographic, clinicopathologic, and risk parameters. Materials and Methods: A total of 403 formalin-fixed paraffin-embedded OSCC specimens from four centers in four regions were obtained. p16 expression was evaluated by immunohistochemistry. The detection of HPV16/18 DNA was performed by polymerase chain reaction. Results: Of all, 172 specimens (42.7\%) were presented with amplifiable extracted DNA. Among these, $62.8 \%$ were positive for p16, $8.1 \%$ were positive for HPV16/18, and 5.8\% were positive for both methods. Of all HPV-positive specimens, HPV18 was detected in 57.1\%; HPV16 in 14.3\%; and HPV16 and 18 (co-infection) in $28.6 \%$. The prevalence of HPV16/18 varied between centers, with the highest rate in the northern center (20.0\%). There was no significant correlation between $\mathrm{p} 16$ expression and HPV16/18. There were no significant associations of p16 expression and/or HPV16/18 with all variables. Conclusions: The prevalence of HPV16/18 infection in OSCC geographically varied in Thailand, with the highest rate in the northern region. Poor correlation between p16 and HPV16/18 suggests p16 not be used as a surrogate marker for HPV-positive OSCC.
\end{abstract}

Keywords: HPV16/18- multicenter study- oral squamous cell carcinoma- p16- Thailand

Asian Pac J Cancer Prev, 21 (11), 3349-3355

\section{Introduction}

Oral squamous cell carcinoma (OSCC) is the most frequent histologic type, accounting for more than $90 \%$ of all oral cancers (Johnson et al., 2011). In Thailand, previous studies in the northern region showed an increasing rate of OSCC in the past two decades (Iamaroon et al., 2004; Komolmalai et al., 2015). Furthermore, the survival rate of Thai patients with OSCC was notably lower than those of the western countries (Pruegsanusak et al., 2012; Gatta et al., 2015; Chitapanarux et al., 2017). Conventionally, the major risk factors for OSCC include tobacco use, alcohol consumption, and betel quid chewing (IARC, 2012b). However, infection with high-risk human papillomavirus (HR-HPV) has been reported as an emerging risk factor for head and neck squamous cell carcinoma (HNSCC) (IARC, 2012a).

HPVs are a heterogeneous group of small doublestranded, circular DNA viruses which can infect epithelial cells of the skin and mucosa (Burd, 2016; Sano and Oridate, 2016). Until now, more than 150 types of HPV are identified and categorized into low-risk and high-risk based on their malignant potential (Sano and Oridate, 2016). LR-HPVs such as types $6,11,40,42,43,44,54$, $61,72,81,89$ were associated with anogenital warts and other benign lesions (Burd, 2016). On the other hand, HR-HPVs such as types 16, 18, 31, 33, 34, 35, 39, 45, 51, $52,56,58,59,66,68$, and 70 were frequently detected in cervical cancer and precancerous lesions (Sano and Oridate, 2016). Moreover, infection with HR-HPVs was found to be associated with cancers at the other sites, including vulva, vagina, penis, anus, oropharynx, and oral cavity (IARC, 2012a). Upon infection, E6 and E7 proteins of the HR-HPVs can cause degradation of p53 protein and inhibit the function of retinoblastoma protein (pRb), causing defects in apoptosis and DNA damage repair, cell cycle dysregulation, and cell immortalization. In addition, the $\mathrm{pRb}$ inhibition by $\mathrm{E} 7$ protein can induce

${ }^{1}$ Department of Oral Biology and Diagnostic Sciences, Faculty of Dentistry, Chiang Mai University, Chiang Mai, Thailand. ${ }^{2}$ Department of Pathology, Faculty of Medicine, Chiang Mai University, Chiang Mai, Thailand. ${ }^{3}$ Department of Stomatology, Faculty of Dentistry, Prince of Songkla University, Songkhla, Thailand. ${ }^{4}$ Department of Oral Pathology, Faculty of Dentistry, Chulalongkorn University, Bangkok, Thailand. ${ }^{5}$ Department of Oral Diagnosis, Faculty of Dentistry, Khon Kaen University, Khon Kaen, Thailand.*For Correspondence: iamaroon@yahoo.com 
an upregulation of p16INK4a (p16) protein, hence p16 expression suggested as a surrogate marker for HPV infection in tissues (Burd, 2016; Sano and Oridate, 2016).

In OSCC, the prevalence of HPV infection was $24.2 \%$ globally (Ndiaye et al., 2014). The most frequent types were HPV16 and 18, while the other HR-HPVs were rarely detected (less than 1\%) (Kreimer et al., 2005; Ndiaye et al., 2014). Individuals with HPV infection had a 4.40-fold increased risk of developing OSCC (Saulle et al., 2015). The HPV prevalence in OSCC varied between geographic regions, with the highest rates among Asian countries (Kreimer et al., 2005; Ndiaye et al., 2014). In Thailand, various results of HPV prevalence (0-57\%) have been reported (Khovidhunkit et al., 2008; Sritippho et al., 2016; Chuerduangphui et al., 2017; Phusingha et al., 2017; Chotipanich et al., 2018).

The distinction between HPV-related and -unrelated HNSCC has been established. The patients with HPVpositive HNSCCs tended to be younger, white, men, and individuals with local $\mathrm{T}$ category and poorly differentiated tumors (Li et al., 2018). Sexual behaviors such as oral sex practice and having multiple lifetime number of oral or genital sexual partners were associated with these cases (Emmett et al., 2018; Laprise et al., 2019). Regarding the prognosis, a significantly better survival and treatment response were observed among those with HPV infection (Li et al., 2018; Tian et al., 2019).

To date, three prophylactic HPV vaccines including Cervarix $^{\mathrm{TM}}$ (bivalent), Gardasil ${ }^{\circledR}$ (quadrivalent), and Gardasil®9 (nonavalent) were approved by the Food and Drug Administration (Takes et al., 2015). HPV vaccination for girls and young women was implemented to prevent cervical cancer in many countries (Herrero et al., 2015; Takes et al., 2015). Some countries such as Australia, Canada, and United States also recommended HPV vaccination in males to prevent anogenital warts and anal cancer (Stanley, 2014; Takes et al., 2015). Considering the higher rate of HPV-related HNSCC among men, HPV vaccination in not only girls, but also boys would be of great importance.

The purposes of this study were to identify the prevalence of HPV types 16 and 18 infection among patients with OSCC in Thailand; and to investigate the associations of p16 expression and HPV16/18 with the demographic, clinicopathologic, and classic risk parameters.

\section{Materials and Methods}

\section{Specimen collection}

A total of 403 formalin-fixed, paraffin-embedded (FFPE) OSCC specimens, collected during January 1999 to January 2019, were received from archives of the Oral Pathology Laboratories, Faculties of Dentistry, Chiang Mai University (CMU, northern region, $n=103$ ); Prince of Songkla University (PSU, southern region, $\mathrm{n}=99$ ); Chulalongkorn University (CU, central region, $\mathrm{n}=108$ ); and Khon Kaen University (KKU, northeastern region $\mathrm{n}=93$ ). Ethical clearances were obtained as follows: CMU (no. 11/2018), PSU (EC6010-31-L-LR), CU (HREC-DCU 2018-005), and KKU (HE612246). All specimens were primary tumors, histologically diagnosed with conventional OSCC or oral verrucous carcinoma (OVC). Age at diagnosis, gender, site of tumor, clinical tumor size, histologic grade; and the history of three classic risk behaviors including tobacco smoking, alcohol consumption, and betel quid chewing were collected from the laboratory records. The histopathologic diagnosis and grade of all specimens were re-evaluated by an experienced pathologist (NL) using the World Health Organization classification (Barnes et al., 2005).

\section{p16 immunohistochemistry (IHC)}

A 3- $\mu \mathrm{m}$ thick section was cut and p16 IHC was performed with the Ventana Benchmark ULTRA autostainer (Ventana Medical Systems, Tucson, AZ, USA) using the CINtec ${ }^{\circledR}$ p16 Histology Kit (clone E6H4, MTM/Roche laboratories AG, Heidelberg, Germany). A positive control of cervical carcinoma was included. p16 immunostaining was examined under a light microscope and scored by an experienced pathologist and an investigator with consensus agreement. The scoring was performed using a 5-tiered system as described by Prigge et al., 2015: none of the tumor cells are stained (-, negative); positive staining in 1-9\% (+/-); 10-49\% $(1+)$; $50-89 \%(2+)$; and $\geq 90 \%(3+)$ of the tumor cells. The kappa scores of 0.87 (95\% CI 0.81-0.93) and 0.80 (95\% CI 0.73-0.87) were evident for intra-observer and inter-observer agreement of p16 scoring, respectively. The specimens with any staining above the background in the invasive parts of tumor were considered p16-positive (Smeets et al., 2007).

\section{HPV16 and 18 DNA detection by polymerase chain reaction $(P C R)$}

Genomic DNA was extracted using the QIAamp ${ }^{\circledR}$ DNA FFPE Tissue Kit (Qiagen GmbH, Hilden, Germany) and subsequently assessed for quantity and purity by the NanoDropTM 2000 Spectrophotometer (Thermo Fisher Scientific, Wilmington, DE, USA). PCR amplification of the house-keeping beta-actin gene was performed to confirm the integrity of extracted DNA and the specimens with negative results were excluded. The amplification of HPV16 and 18 DNA was then performed using the forward and reverse primers specific to the E6 gene as described in a previously study (Sritippho et al., 2016). A $25-\mu$ PCR reaction contained $1 \times$ PCR buffer, $0.2 \mathrm{mM}$ dNTP mixture, $1.5 \mathrm{mM} \mathrm{MgCl}_{2}, 0.2 \mu \mathrm{M}$ of each primer, 1 unit of PlatinumTM Taq DNA polymerase (InvitrogenTM, Life Technologies, São Paulo, Brazil), and $5 \mu 1$ of DNA template. DNA extracted from SiHa and HeLa cell lines was included as a positive control for HPV16 and HPV18, respectively. A negative control was included in each run. The PCR conditions were $95^{\circ} \mathrm{C}$ for $5 \mathrm{~min}, 45$ cycles of $94^{\circ} \mathrm{C}$ for $30 \mathrm{~s}, 55^{\circ} \mathrm{C}$ for $30 \mathrm{~s}$, and $72^{\circ} \mathrm{C}$ for $30 \mathrm{~s}$, and a final extension at $72^{\circ} \mathrm{C}$ for $7 \mathrm{~min}$. The PCR products were analyzed by electrophoresis on $1.5 \%$ agarose gel and photographed using the ChemiDocTM Touch Imaging System (Bio-Rad Laboratories, Hercules, CA, USA).

\section{Statistical analysis}

The statistical analysis was performed using the IBM ${ }^{\circledR}$ 
SPSS $®$ Statistics version 23. The Cohen's kappa test was used to evaluate the concordance between p16 IHC and HPV16/18 PCR. The Chi-square or Fisher's exact test was used to analyze the associations of p16 expression and HPV16/18 with age category, sex, site of tumor, clinical tumor size, histopathologic variant and grade, and the risk behaviors. The results with $p$ value less than 0.05 were considered statistically significant.

\section{Results}

Of all, DNAs extracted from 172 specimens (42.7\%) were positive for beta-actin gene and further analyzed. The median age at diagnosis of all patients was 66 . The male-to-female ratio was 1:1.2. The demographic, clinicopathologic, and risk factor data for all cases are shown in Table 1.

The p16 scoring in representative examples is displayed in Figure 1. Of all 172 specimens, 62.8\% showed p16 staining in the tumor cells. For all centers, HPV16 and/or 18 DNA was detected in 14 specimens $(8.1 \%)$. Among these, $2(14.3 \%)$ were positive for HPV16, $8(57.1 \%)$ were positive for HPV18, and $4(28.6 \%)$ were positive for both HPV16 and HPV18 (co-infection). Regarding each center, HPV16/18 was found in the specimens from the northern center $(20.0 \%)$ and the southern center $(6.9 \%)$, while it was not detected in those from the central and northeastern centers. The PCR products of representative cases are shown in Figure 2. The PCR protocols in this study were validated using serially diluted DNA extracted from $\mathrm{SiHa}$ and $\mathrm{HeLa}$ cell lines and yielded detection limits of 6 copies/ $\mu$ l for HPV16 and 322 copies/ $\mu$ l for HPV18.

The findings by both assays are summarized in Table 2. Of all specimens, $5.8 \%$ were positive for both methods. The concordant between the two assays was poor $(\kappa=0.023, p=0.485)$. There were no significant associations of p16 and/or HPV16/18 with the demographic, clinicopathologic, and risk factor variables (Table 1).

\section{Discussion}

Globally, the pooled HPV prevalence in OSCC ranged from 16.9 to $24.2 \%$ (Kreimer et al., 2005; Ndiaye et al., 2014; Saulle et al., 2015). In this study, the prevalence of HPV16 and/or 18 was $8.1 \%$. When compared with

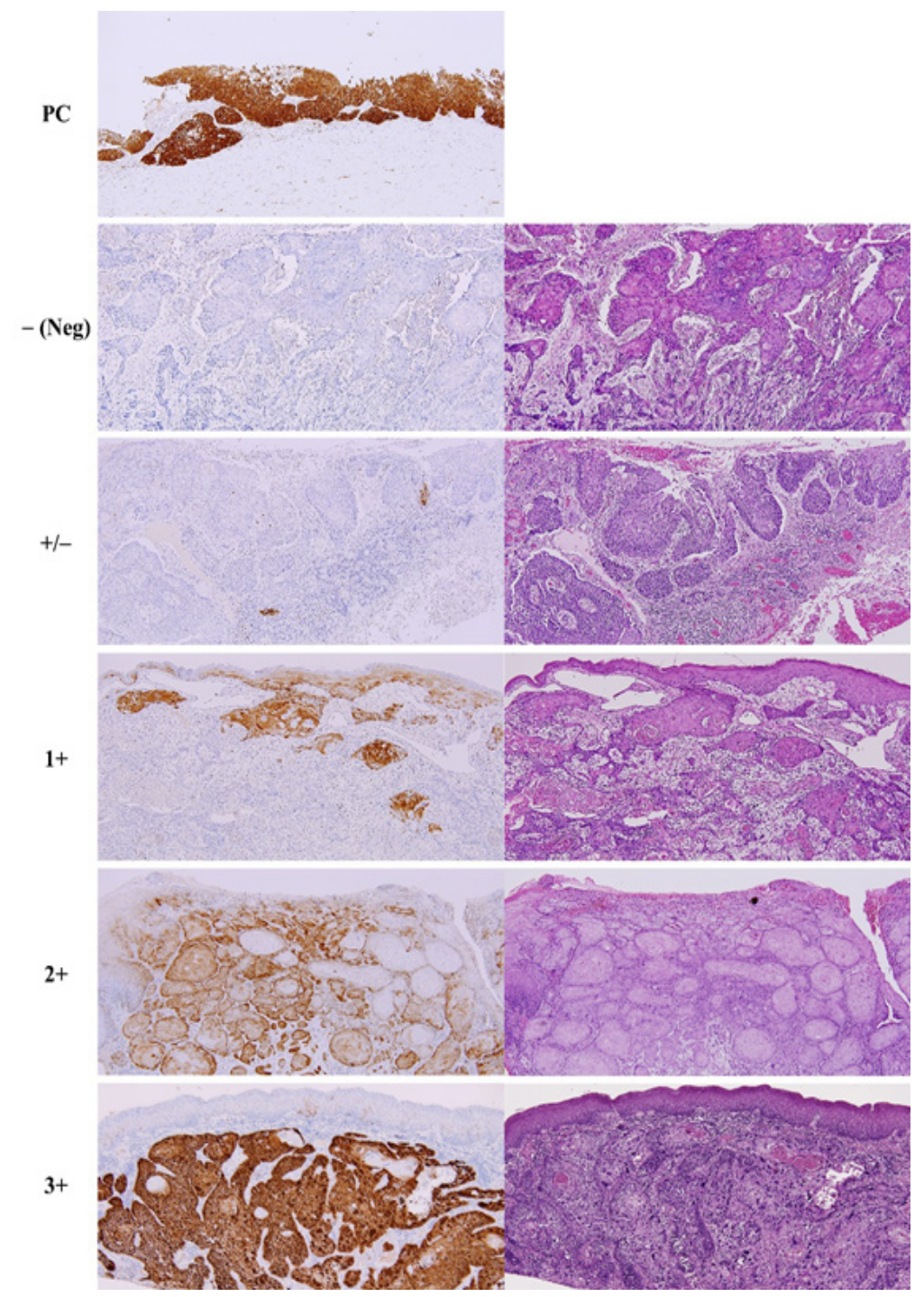

Figure 1. p16 Expression in Cervical Carcinoma (Positive Control, PC) and p16 Scoring in Representative OSCC Specimens. Left panel: p16 IHC; right panel: H\&E, $\times 100$ original magnification 
Table 1. Demographic, Clinicopathologic, and Risk Behavior Data and Their Associations with p16 Expression and HPV16/18 DNA

\begin{tabular}{|c|c|c|c|c|c|c|c|c|c|c|c|}
\hline \multirow[t]{2}{*}{ Variables } & \multicolumn{2}{|c|}{$\begin{array}{l}\text { No. cases } \\
(\mathrm{N}=172)\end{array}$} & \multicolumn{2}{|c|}{ p16 IHC+ } & \multirow[b]{2}{*}{$\mathrm{p}^{\dagger}$} & \multicolumn{3}{|c|}{ HPV16/18 DNA+ } & \multicolumn{3}{|c|}{ p16 IHC+ and HPV16/18 DNA+ } \\
\hline & $\mathrm{n}$ & $(\%)$ & $\mathrm{n}$ & $(\%+)$ & & $\mathrm{n}$ & $(\%+)$ & $\mathrm{p}^{\dagger}$ & $\mathrm{n}$ & $(\%+)$ & $\mathrm{p}^{\dagger}$ \\
\hline Age category (year) & & & & & 0.301 & & & 0.145 & & & 0.669 \\
\hline$<50$ & 24 & 14 & 17 & 70.8 & & 1 & 4.2 & & 1 & 4.2 & \\
\hline $50-69$ & 90 & 52.3 & 59 & 65.6 & & 11 & 12.2 & & 7 & 7.8 & \\
\hline$\geq 70$ & 58 & 33.7 & 32 & 55.2 & & 2 & 3.4 & & 2 & 3.4 & \\
\hline Gender & & & & & 0.338 & & & 0.845 & & & 0.515 \\
\hline Male & 78 & 45.3 & 52 & 66.7 & & 6 & 7.7 & & 6 & 7.7 & \\
\hline Female & 94 & 54.7 & 56 & 59.6 & & 8 & 8.5 & & 4 & 4.3 & \\
\hline Site & & & & & 0.509 & & & 0.395 & & & 0.186 \\
\hline Tongue & 46 & 26.7 & 28 & 60.9 & & 6 & 13 & & 5 & 10.9 & \\
\hline Gum/alveolar mucosa & 70 & 40.7 & 44 & 62.9 & & 5 & 7.1 & & 3 & 4.3 & \\
\hline Buccal/labial mucosa & 21 & 12.2 & 10 & 47.6 & & 1 & 4.8 & & 0 & 0 & \\
\hline Floor of mouth & 8 & 4.7 & 6 & 75 & & 1 & 12.5 & & 1 & 12.5 & \\
\hline Retromolar area & 7 & 4.1 & 6 & 85.7 & & 1 & 14.3 & & 1 & 14.3 & \\
\hline Other sites & 20 & 11.6 & 14 & 70 & & 0 & 0 & & 0 & 0 & \\
\hline Clinical tumor size $(\mathrm{cm})$ & & & & & $0.566 \$$ & & & $0.441 \ddagger$ & & & $0.302 \ddagger$ \\
\hline$\leq 2$ & 49 & 28.5 & 29 & 59.2 & & 2 & 4.1 & & 1 & 2 & \\
\hline$>2$ and $\leq 4$ & 34 & 19.8 & 24 & 70.6 & & 4 & 11.8 & & 3 & 8.8 & \\
\hline$>4$ & 16 & 9.3 & 10 & 62.5 & & 1 & 6.3 & & 1 & 6.3 & \\
\hline Missing data & 73 & 42.4 & & & & & & & & & \\
\hline Histologic characteristics & & & & & 0.374 & & & 0.725 & & & 0.474 \\
\hline MIC SCC & 9 & 5.2 & 7 & 77.8 & & 0 & 0 & & 0 & 0 & \\
\hline WD SCC & 127 & 73.8 & 74 & 58.3 & & 11 & 8.7 & & 7 & 5.5 & \\
\hline MD SCC & 22 & 12.8 & 17 & 77.3 & & 2 & 9.1 & & 2 & 9.1 & \\
\hline PD SCC & 6 & 3.5 & 4 & 66.7 & & 1 & 16.7 & & 1 & 16.7 & \\
\hline $\mathrm{VC}$ & 8 & 4.7 & 6 & 75 & & 0 & 0 & & 0 & 0 & \\
\hline Tobacco smoking & & & & & $0.108 \$$ & & & $>0.999 \$$ & & & $0.643 \ddagger$ \\
\hline Ever & 26 & 15.1 & 22 & 84.6 & & 5 & 19.2 & & 5 & 19.2 & \\
\hline Never & 12 & 7 & 7 & 58.3 & & 2 & 16.7 & & 1 & 8.3 & \\
\hline Missing data & 134 & 77.9 & & & & & & & & & \\
\hline Alcohol consumption & & & & & $>0.999$ & & & $0.591 \ddagger$ & & & $>0.999 \ddagger$ \\
\hline Ever & 9 & 5.2 & 6 & 66.7 & & 1 & 11.1 & & 1 & 11.1 & \\
\hline Never & 11 & 6.4 & 7 & 63.6 & & 3 & 27.3 & & 2 & 18.2 & \\
\hline Missing data & 152 & 88.4 & & & & & & & & & \\
\hline Betel quid chewing & & & & & $>0.999 \$$ & & & $0.609 \$$ & & & $0.544 \ddagger$ \\
\hline Ever & 13 & 7.6 & 8 & 61.5 & & 2 & 15.4 & & 1 & 7.7 & \\
\hline Never & 9 & 5.2 & 6 & 66.7 & & 3 & 33.3 & & 2 & 22.2 & \\
\hline Missing data & 150 & 87.2 & & & & & & & & & \\
\hline
\end{tabular}

MD, moderately differentiated; MIC, microinvasive; PD, poorly differentiated; SCC, squamous cell carcinoma; VC, verrucous carcinoma; WD, well differentiated; $\uparrow$, Chi-square or Fisher's exact test; $\$$, The cases with missing data were excluded.

Table 2. Cross-Tabulation Table of p16 Expression by IHC and HPV16/18 Detection by PCR in the OSCC Specimens

\begin{tabular}{lccc}
\hline & HPV16/18 DNA + & HPV16/18 DNA- & Total \\
\hline p16+ & 10 & 98 & 108 \\
p16- & 4 & 60 & 64 \\
Total & 14 & 158 & 172 \\
\hline
\end{tabular}

previous studies in Thailand, the rate is similar to a study (7.7\%) (Chotipanich et al., 2018), but lower than other studies (15.8\%-57\%) (Sritippho et al., 2016; Chuerduangphui et al., 2017; Phusingha et al., 2017). The discrepancy between studies may reflect the differences in specimen selection, methods of HPV detection, HPV genotypes inclusion, and trend of risk behaviors.

Regarding HPV subtypes, most studies reported that HPV16 was the most predominant type in OSCC, 


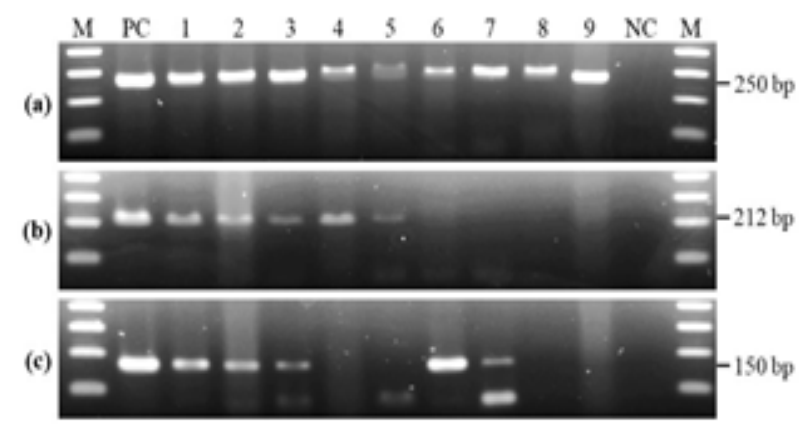

Figure 2. PCR Amplifications of Beta-Actin (a), HPV16 E6 (b), and HPV18 E6 (c) Genes. Lane M: 100-bp DNA ladder marker; lane PC: positive control; lanes 1-3: HPV16 and 18-positive specimens; lanes 4 and 5: HPV16-positive, HPV18-negative specimens; lanes 6 and 7, HPV16-negative, HPV18-positive specimens; lanes 8 and 9: HPV16 and 18-negative specimens; lane $\mathrm{NC}$ : negative control

followed by HPV18 (Kreimer et al., 2005; Ndiaye et al., 2014). On the contrary, the prevalence of HPV18 in this study was higher than that of HPV16. Nevertheless, a higher prevalence of HPV18 in OSCC cases in relation to HPV16 was also reported among some studies in South Asian countries (Kulkarni et al., 2011; Zil et al., 2018).

When only OVC cases is considered, the HR-HPV prevalence in previous studies ranged from 14.3 to $47.8 \%$ (Fujita et al., 2008; Saghravanian et al., 2015; Sritippho et al., 2016). However, we did not detect HPV16/18 among the OVC cases, which may be accounted by the limited numbers of these specimens. Moreover, other HR-HPVs previously detected in VCs such as types 33, 35, and 45 (Fujita et al., 2008; del Pino et al., 2012) were excluded.

Among centers, the highest prevalence of HPV16/18 was observed in the northern center. We did not detect HPV16/18 in the specimens from central and northeastern centers, which is in contrast with some reports from these two regions (Khovidhunkit et al., 2008; Chuerduangphui et al., 2017; Phusingha et al., 2017; Chotipanich et al., 2018). There are several possible explanations for the discrepant rates between centers. The differences in method and period of specimen collection may affect the rate of DNA degradation. The demographic, clinicopathologic, and risk behavior variables were also varied among centers. Moreover, our results may reflect the general prevalence of HPV infection in each region. According to a multicenter study, the highest incidence of cervical cancer was observed among northern population (Bray et al., 2017). Another study reported the highest prevalence of cervical HPV infection in southern region (97.1\%), followed by northern region $(91.3 \%)$, northeastern region (87.9\%), and the lowest in the central region (78.6\%) (Suthipintawong et al., 2011).

p16 IHC is widely used as an indirect marker for transcriptionally active-HPV due to its high sensitivity and feasibility with FFPE materials (Prigge et al., 2017). In 2018, the College of American Pathologists recommended the use of p16 IHC as a surrogate marker for HR-HPV testing in all new patients diagnosed with OPSCC, while for patients with non-oropharyngeal HNSCC, such testing should not be included in the routine practice (Lewis et al., 2018). In this study, the concordance between p16 expression and HPV16/18 was poor, which is similar to some previous studies (Ramshankar et al., 2014; Zafereo et al., 2016; Minami et al., 2017). Therefore, p16 may not be appropriate as a surrogate marker for HR-HPV infection in OSCCs. In addition, discrepant results between these two methods were also noted in our study. We found that $28.6 \%$ of all HPV16/18-positive specimens did not show any p16 staining in the tumor cells, which may imply a bystander HPV16/18 infection or an active HPV infection without $\mathrm{p} 16$ upregulation. The latter assumption was also seen in some previous studies which reported a subset of HNSCC cases with HPV E6/E7 mRNA-positive but lack of p16 expression (Hoffmann et al., 2012; Minami et al., 2017). Conversely, among all HPV16/18-negative specimens, p16 expression was observed in $62.0 \%$. Infection with other HR-HPV types and an upregulation of p16 by alternate pathways may be attributable for this result. Nevertheless, an upregulation of p16 independent of HPV infection has also been reported in a subset of HNSCCs (Sgaramella et al., 2015; Dreyer et al., 2017).

Regarding the patient profiles, our results demonstrated no significant associations between HPV status and all parameters, which are in line with some studies (Duray et al., 2012; Kruger et al., 2014; de Abreu et al., 2018). On the contrary, other studies reported significantly higher rates of HPV infection among younger patients (Zhang et al., 2004; Sritippho et al., 2016); male patients (Zhang et al., 2004; Awan et al., 2017); tumors at the tongue (Phusingha et al., 2017); early TNM stage (stage I and II) and poorly differentiated tumors (Zhao et al., 2009; Lingen et al., 2013); and those with no history of tobacco smoking (Zhao et al., 2009) and no oral (smokeless) tobacco usage (Kane et al., 2015).

There are some limitations in the present study. First, the wide range of year collection of specimens could affect the quality of DNA. Second, since all data were collected from the history records; thus, there were several missing data regarding the clinical tumor size and the classic risk behaviors. Therefore, these may compromise the analyses of the clinical and risk behavior profiles.

In conclusion, the prevalence of HPV16/18 infection in OSCC varied between different regions in Thailand, with the highest rate among the northern population. The prevalence of HPV18 was twice higher than that of HPV16. The concordance between these two methods was poor. Further studies are needed to establish the association between HPV infection and sexual behaviors among Thai population. Moreover, the difference in survival outcome of Thai patients with OSCC regarding their HPV status requires further investigation.

\section{Acknowledgments}

This study was supported by a Thai Health Promotion Foundation project fund and a research grant for graduate students, Faculty of Dentistry, Chiang Mai University, Thailand. The authors would like to acknowledge Dr. Wiyada Dankai and Dr. Kittisak Buddhachat for their technical assistance and Dr. Utaiwan Utaipat for providing the HPV16 and 18 cell lines. 
Statement conflict of Interest

The authors declare no conflict of interest.

\section{References}

Awan MS, Irfan B, Zahid I, et al (2017). Comparison of polymerase chain reaction and immunohistochemistry assays for analysing human papillomavirus infection in oral squamous cell carcinoma. JClin Diagn Res, 11, XC10-XC3.

Barnes L, Eveson JW, Reichart P (2005). World Health Organization Classification of Tumours. Pathology and Genetics of Head and Neck Tumours, IARC Press, Lyon.

Bray F, Colombet M, Mery L, et al (2017). Cancer Incidence in Five Continents, Vol. XI [Online]. Lyon: International Agency for Research on Cancer. [Accessed 1 September 2019].

Burd EM (2016). Human papillomavirus laboratory testing: the Changing Paradigm. Clin Microbiol Rev, 29, 291-319.

Chitapanarux I, Traisathit P, Komolmalai N, et al (2017). Tenyear outcome of different treatment modalities for squamous cell carcinoma of oral cavity. Asian Pac J Cancer Prev, 18, 1919-24.

Chotipanich A, Siriarechakul S, Mungkung OO (2018). Role of high-risk human papillomavirus in the etiology of oral and oropharyngeal cancers in Thailand: A case-control study. SAGE Open Med, 2018, 6 .

Chuerduangphui J, Pientong C, Patarapadungkit N, et al (2017). Amplification of EGFR and cyclin D1 genes associated with human papillomavirus infection in oral squamous cell carcinoma. Med Oncol, 34, 148.

de Abreu PM, Có ACG, Azevedo PL, et al (2018). Frequency of HPV in oral cavity squamous cell carcinoma. BMC Cancer, 18, 324-.

del Pino M, Bleeker MC, Quint WG, et al (2012). Comprehensive analysis of human papillomavirus prevalence and the potential role of low-risk types in verrucous carcinoma. Mod Pathol, 25, 1354-63.

Dreyer JH, Hauck F, Barros MHM, et al (2017). pRb and CyclinD1 complement p16 as immunohistochemical surrogate markers of HPV infection in head and neck cancer. Appl Immunohistochem Mol Morphol, 25, 366-73.

Duray A, Descamps G, Decaestecker C, et al (2012). Human papillomavirus DNA strongly correlates with a poorer prognosis in oral cavity carcinoma. Laryngoscope, 122, 1558-65.

Emmett S, Boros S, Whiteman DC, et al (2018). Sexual behaviour, HPV status and p16(INK4a) expression in oropharyngeal and oral cavity squamous cell carcinomas: a case-case comparison study. J Gen Virol, 99, 783-9.

Fujita S, Senba M, Kumatori A, et al (2008). Human papillomavirus infection in oral verrucous carcinoma: Genotyping Analysis and Inverse Correlation with p53 Expression. Pathobiology, 75, 257-64.

Gatta G, Botta L, Sánchez MJ, et al (2015). Prognoses and improvement for head and neck cancers diagnosed in Europe in early 2000s: The EUROCARE-5 population-based study. Eur J Cancer, 51, 2130-43.

Herrero R, Gonzalez P, Markowitz LE (2015). Present status of human papillomavirus vaccine development and implementation. Lancet Oncol, 16, e206-16.

Hoffmann M, Tribius S, Quabius ES, et al (2012). HPV DNA, E6*ImRNA expression and p16INK4A immunohistochemistry in head and neck cancer - how valid is p16INK4A as surrogate marker?. Cancer Lett, 323, 88-96.

Iamaroon A, Pattanaporn K, Pongsiriwet S, et al (2004). Analysis of 587 cases of oral squamous cell carcinoma in northern Thailand with a focus on young people. Int J Oral Maxillofac
Surg, 33, 84-8.

IARC (2012a). IARC Monographs on the Evaluation of Carcinogenic Risks to Humans: Volume 100B. Biological Agents, Lyon, France, International Agency for Research on Cancer.

IARC (2012b). IARC Monographs on the Evaluation of Carcinogenic Risks to Humans: Volume 100E. Personal Habits and Indoor Combustions, Lyon, France, International Agency for Research on Cancer.

Johnson NW, Jayasekara P, Amarasinghe AA (2011). Squamous cell carcinoma and precursor lesions of the oral cavity: epidemiology and aetiology. Periodontol, 57, 19-37.

Kane S, Patil VM, Noronha V, et al (2015). Predictivity of human papillomavirus positivity in advanced oral cancer. Indian $J$ Cancer, 52, 403-5.

Khovidhunkit SO, Buajeeb W, Sanguansin S, et al (2008). Detection of human papillomavirus in oral squamous cell carcinoma, leukoplakia and lichen planus in Thai patients. Asian Pac J Cancer Prev, 9, 771-5.

Komolmalai N, Chuachamsai S, Tantiwipawin S, et al (2015). Ten-year analysis of oral cancer focusing on young people in northern Thailand. J Oral Sci, 57, 327-34.

Kreimer AR, Clifford GM, Boyle P, et al (2005). Human papillomavirus types in head and neck squamous cell carcinomas worldwide: a systematic review. Cancer Epidemiol Biomarkers Prev, 14, 467-75.

Kruger M, Pabst AM, Walter C, et al (2014). The prevalence of human papilloma virus (HPV) infections in oral squamous cell carcinomas: a retrospective analysis of 88 patients and literature overview. J Craniomaxillofac Surg, 42, 1506-14.

Kulkarni SS, Kulkarni SS, Vastrad PP, et al (2011). Prevalence and distribution of high risk human papillomavirus (HPV) Types 16 and 18 in Carcinoma of cervix, saliva of patients with oral squamous cell carcinoma and in the general population in Karnataka, India. Asian Pac J Cancer Prev, 12, 645-8.

Laprise C, Madathil SA, Schlecht NF, et al (2019). Increased risk of oropharyngeal cancers mediated by oral human papillomavirus infection: Results from a Canadian study. Head Neck, 41, 678-85.

Lewis JS, Jr., Beadle B, Bishop JA, et al (2018). Human papillomavirus testing in head and neck carcinomas: Guideline From the College of American Pathologists. Arch Pathol Lab Med, 142, 559-97.

Li H, Torabi SJ, Yarbrough WG, et al (2018). Association of Human Papillomavirus Status at Head and Neck Carcinoma Subsites With Overall Survival. JAMA Otolaryngol Head Neck Surg, 144, 519-25.

Lingen MW, Xiao W, Schmitt A, et al (2013). Low etiologic fraction for high-risk human papillomavirus in oral cavity squamous cell carcinomas. Oral Oncol, 49, 1-8.

Minami K, Kogashiwa Y, Ebihara Y, et al (2017). Human papillomavirus and p16 protein expression as prognostic biomarkers in mobile tongue cancer. Acta Otolaryngol, 137, 1121-6.

Ndiaye C, Mena M, Alemany L, et al (2014). HPV DNA, E6/E7 mRNA, and p16INK4a detection in head and neck cancers: a systematic review and meta-analysis. Lancet Oncol, 15, 1319-31.

Phusingha P, Ekalaksananan T, Vatanasapt P, et al (2017). Human papillomavirus (HPV) infection in a case-control study of oral squamous cell carcinoma and its increasing trend in northeastern Thailand. J Med Virol, 89, 1096-101.

Prigge ES, Arbyn M, von Knebel Doeberitz M, et al (2017). Diagnostic accuracy of p16INK4a immunohistochemistry in oropharyngeal squamous cell carcinomas: A systematic review and meta-analysis. Int J Cancer, 140, 1186-98. 
Prigge ES, Toth C, Dyckhoff G, et al (2015). p16(INK4a) /Ki-67 co-expression specifically identifies transformed cells in the head and neck region. Int J Cancer, 136, 1589-99.

Pruegsanusak K, Peeravut S, Leelamanit V, et al (2012). Survival and prognostic factors of different sites of head and neck cancer: an analysis from Thailand. Asian Pac J Cancer Prev, 13, 885-90.

Ramshankar V, Soundara VT, Shyamsundar V, et al (2014) Risk stratification of early stage oral tongue cancers based on HPV status and p16 immunoexpression. Asian Pac J Cancer Prev, 15, 8351-9.

Saghravanian N, Ghazi N, Meshkat Z, et al (2015). Human papillomavirus in oral leukoplakia, verrucous carcinoma, squamous cell carcinoma, and normal mucous membrane. Oman Med J, 30, 455-60.

Sano D, Oridate N (2016). The molecular mechanism of human papillomavirus-induced carcinogenesis in head and neck squamous cell carcinoma. Int J Clin Oncol, 21, 819-26.

Saulle R, Semyonov L, Mannocci A, et al (2015). Human papillomavirus and cancerous diseases of the head and neck: a systematic review and meta-analysis. Oral Dis, 21, 417-31.

Sgaramella N, Coates PJ, Strindlund K, et al (2015). Expression of p16 in squamous cell carcinoma of the mobile tongue is independent of HPV infection despite presence of the HPV-receptor syndecan-1. Br J Cancer, 113, 321-6.

Smeets SJ, Hesselink AT, Speel EJ, et al (2007). A novel algorithm for reliable detection of human papillomavirus in paraffin embedded head and neck cancer specimen. Int $J$ Cancer, 121, 2465-72.

Sritippho T, Pongsiriwet S, Lertprasertsuke N, et al (2016). p16 - a possible surrogate marker for high-risk human papillomaviruses in oral cancer?. Asian Pac J Cancer Prev, 17, 4049-57.

Stanley M (2014). HPV vaccination in boys and men. Hum Vaccin Immunother, 10, 2109-11.

Suthipintawong C, Siriaunkgul S, Tungsinmunkong K, et al (2011). Human papilloma virus prevalence, genotype distribution, and pattern of infection in Thai women. Asian Pac J Cancer Prev, 12, 853-6.

Takes RP, Wierzbicka M, D'Souza G, et al (2015). HPV vaccination to prevent oropharyngeal carcinoma: What can be learned from anogenital vaccination programs?. Oral Oncol, 51, 1057-60.

Tian S, Switchenko JM, Jhaveri J, et al (2019). Survival outcomes by high-risk human papillomavirus status in nonoropharyngeal head and neck squamous cell carcinomas: A propensity-scored analysis of the National Cancer Data Base. Cancer, 125, 2782-93.

Zafereo ME, Xu L, Dahlstrom KR, et al (2016). Squamous cell carcinoma of the oral cavity often overexpresses p16 but is rarely driven by human papillomavirus. Oral Oncol, 56, 47-53.

Zhang ZY, Sdek P, Cao J, et al (2004). Human papillomavirus type 16 and 18 DNA in oral squamous cell carcinoma and normal mucosa. Int J Oral Maxillofac Surg, 33, 71-4.

Zhao D, Xu QG, Chen XM, et al (2009). Human papillomavirus as an independent predictor in oral squamous cell cancer. Int J Oral Sci, 1, 119-25.

Zil ER, Baig S, Zaman U, et al (2018). Human papilloma virus 16/18: Fabricator of trouble in oral squamous cell carcinoma. Int J Infect Dis, 69, 115-9.

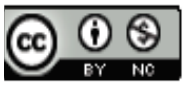

This work is licensed under a Creative Commons Attribution-

Non Commercial 4.0 International License. 